\title{
A General Theorem on the Nine-points Circle.
}

By V. Ramaswami Aiyar, M.A.

Theorem : If any conic be inscribed in a given triangle and a confocal to it pass through the circumcentre, then the circle through the intersection of these two confocals touches the nine-points circle of the triangle.

Demoystration : Let $\mathrm{X}$ (Fig. 10) be any conic inscribed in the triangle $\mathrm{ABC} ; \mathrm{O}, \mathrm{H}, \mathrm{N}$ its circumcentre, orthocentre and ninepoints centre; let $R$ be the circumradius.

Let $\mathrm{X}$ be any conic inscribed in the triangle $A B C ; P, Q$ its foci ; $M$ its centre; and $\alpha, \beta$ its semi-axes.

Let $\mathrm{Y}$ be a confocal to $\mathrm{X}$ passing through the circumcentre $\mathrm{O}$; and let $\rho$ be the radius of the circle through the intersections of $\mathrm{X}$ and $\mathrm{Y}$. We have to show that this circle touches the nine-points circle of $\mathrm{ABC}$.

This will be proved if we show that $\rho=\frac{1}{2} R \pm M N$. This can be shown with the aid of the following propositions :

Lemma $I$. The circle passing through the intersections of the confocals

$x^{2} / a^{2}+y^{2} / b^{2}=1$ and $x^{2} /\left(a^{2}+\lambda\right)+y^{2} /\left(b^{2}+\lambda\right)=1$ is $x^{2}+g^{2}=a^{2}+b^{2}+\lambda$; this circle is the mutual orthoptic circle of the two confocals.

Lemma II. If $\mathrm{P}$ and $\mathrm{Q}$ be the foci of any conic $\mathrm{X}$ inscribed in a triangle $\mathrm{ABO}$ we have

$$
\left(R^{2}-O P^{2}\right)\left(R^{2}-O Q^{2}\right)=4 \beta^{2} R^{2} \text {. }
$$

[Professor Genese, Educatianal Times, Q. 10879 ; for a solution see p. 37, Vol. 57 of the Mathematical Reprints.]

Lemma III. Any conic $\mathrm{X}$ being inscribed in a triangle $\mathrm{ABC}$ its director circle cuts the polar circle of the triangle orthogonally. The centre of the polar circle is the orthocentre $H$ and the square of its radius

$$
=-\frac{1}{2}\left(\mathrm{R}^{2}-\mathrm{OH}^{2}\right) \text {. }
$$

Now by lemma $I$. applied to the confocals $X$ and $Y$ we have

$$
\begin{aligned}
\rho^{2} & =\beta^{2}+\left(\frac{O P \pm O Q}{2}\right)^{2} \\
& =\frac{1}{4}\left(O P^{2}+O A^{2}+4 \beta^{2}\right) \pm \frac{1}{2} O P . O Q \quad .
\end{aligned}
$$


Lemma II. gives

$$
\mathrm{R}^{4}-\mathrm{R}^{2}\left(\mathrm{OP}^{2}+\mathrm{OQ}^{2}+4 \beta^{2}\right)+\mathrm{OP}^{2} . O Q^{2}=0
$$

In (1) and (2) the expression $O P^{2}+O Q^{2}+4 \beta^{2}$ occurs; this is readily seen to be equal to $2\left(a^{2}+\beta^{2}+\mathrm{OM}^{2}\right)$

Again by lemma III. we have

$$
\begin{aligned}
\left(\alpha^{2}+\beta^{2}\right)-\frac{1}{2}\left(R^{2}-O H^{2}\right)=M H^{\prime \prime} & \\
\therefore \quad a^{2}+\beta^{2}+O M^{2} & =O M^{2}+M^{2}+\frac{1}{2}\left(R^{2}-O H^{2}\right) \\
& =\frac{1}{2} R^{2}+2 M N^{2} .
\end{aligned}
$$

By (3) and (4) we have

$$
O P^{2}+O Q^{2}+4 \beta^{2}=R^{2}+4 M^{2}
$$

Using this in (2) we get a pretty simple result

$$
O P . O Q=2 R . M N
$$

Now making use of (5) and (6) in equation (1) we get

$$
\begin{aligned}
\rho^{2} & =\frac{1}{4} R^{2}+M^{2} \pm R . M N \\
& =\left(\frac{1}{2} R \pm M N\right)^{2}
\end{aligned}
$$

$\therefore \rho=\frac{1}{2} \mathrm{R} \pm \mathrm{MN}$; and the theorem is proved.

Corollary. - A beautiful theorem, due to $\mathrm{Mr}$ M'Cay, of which Feverbach's theorem is a particular case, is itself a particular case of the theorem now given; $\mathrm{Mr}$ M'Cay's theorem may be thus stated: "If either axis of a conic inscribed in a given triangle pass through the circumcentre, then the corresponding auxiliary circle of the conic touches the nine-points circle of the triangle." [See Casey's Conics, 2nd Edition, p. 329.]

\section{On the Geometical Represetation of Elliptic Integrals of the First Kind.}

By Alex. Morgan, M.A., B.Sc.

[See page 2 of present volume.]

Dr T. B. Sprague, M.A., F.R.S.E., was elected President in room of the Rev. John Wilson, deceased. 